\title{
Morphophysiological responses of Crambe abyssinica Hochst. lineages submitted to water deficit during flowering
}

\author{
P.C.S. BRAGA (iD, J.P.R. MARTINS ${ }^{+}$(D) , R. BONOMO (iD, and A.R. FALQUETO \\ Department of Agrarian and Biological Sciences, Federal University of Espírito Santo, Litorâneo, \\ 29932-540 São Mateus, ES, Brazil*
}

\begin{abstract}
Water deficit (WD) at the start of the flowering stage can negatively affect the productivity of plants. The aim was to investigate the morphophysiological strategies of two crambe lineages (FMS CR 1326 and 1307) submitted to WD during the flowering stage and their connection with the progeny's germination. Plants were submitted to WD at the start of flowering for $12 \mathrm{~d}$ and then were irrigated again (water resumption, WR). As a control, plants were cultivated with uninterrupted daily irrigation. Under WD, reductions were observed in the stomatal conductance, the number of xylem vessels, and the mass of grains. Positive K- and L-bands occurred, indicating lower stability and efficiency in the use of energy under WD. In the WR period, plants presented photochemical recovery. WD induced less vigorous seeds. FMS CR 1307 had the highest capacity to maintain its photochemical performance, due to alterations in water conductivity, resulting in greater seed production and vigor.
\end{abstract}

Keywords: chlorophyll $a$ fluorescence; grain yield; plant anatomy; progeny; water stress.

\section{Introduction}

Crambe abyssinica Hochst. (crambe) is an oilseed plant belonging to the Brassicaceae family, with promising traits for industrial use due to the high contents of oil (30-35\%) and erucic acid (63-64\%) (Wang et al. 2000, Lalas et al. 2012), meaning it has huge potential, especially for the production of biodiesel (Oliveira et al.

\section{Highlights}

- Lineage FMS CR 1326 had lower photochemical adjustment under WD

- FMS CR 1307 had the best photochemical performance due to alterations in water conductivity

- FMS CR 1307 had greater progeny seed production and vigor
Received 10 June 2021

Accepted 7 July 2021

Published online 9 August 2021

${ }^{+}$Corresponding author

e-mail: jprmartinss@yahoo.com.br

Abbreviations: ABS/RC - absorption flux per RC; Chl - chlorophyll; $\mathrm{CI}$ - continuously irrigated plants; $\mathrm{DI}_{0} / \mathrm{RC}^{-}$dissipated energy flux per $\mathrm{RC} ; \mathrm{ET}_{0} / \mathrm{RC}$ - electron transport flux per RC; $\mathrm{F}_{0}$ - minimal fluorescence yield of the dark-adapted state; $\mathrm{F}_{\mathrm{I}}-$ fluorescence intensity at $30 \mathrm{~ms} ; \mathrm{F}_{\mathrm{J}}$ - fluorescence intensity at $2 \mathrm{~ms} ; \mathrm{F}_{\mathrm{K}}$ - fluorescence intensity at $0.3 \mathrm{~ms} ; \mathrm{F}_{\mathrm{m}}$ - maximal fluorescence yield of the dark-adapted state; $\mathrm{F}_{\mathrm{V}} / \mathrm{F}_{0}$ - ratio of photochemical to nonphotochemical quantum efficiencies (PSII potential activity); $g_{\mathrm{s}}-$ stomatal conductance; GSI - germination speed index; $\mathrm{M}_{0}$ - number of closed and/or inactive reaction centers; OEC - oxygen-evolving complex; $\mathrm{PI}_{(\mathrm{ABS})}$ - performance index based on absorption; $\mathrm{PI}_{(\mathrm{TOTAL})}$ - overall performance index, which measures the performance up until the final electron acceptors of PSI; RC - reaction center; RC/ABS - total number of active reaction centers per absorption; S1CI - control plants - progeny of continuously irrigated plants; S1WD - progeny of plants submitted to WD for $12 \mathrm{~d}$; Sm - assumed proportional to the number of reduction and oxidation of one $\mathrm{Q}_{\mathrm{A}}{ }^{-}$molecule during the fast OJIP transient, and therefore related to the number of electron carriers per electron transport chain; $\mathrm{TR}_{0} / \mathrm{RC}$ - trapping flux per $\mathrm{RC}$; WD - water deficit; WR - water resumption; $\% \mathrm{G}$ - germination percentage; $\varphi \mathrm{D}_{0}$ - quantum yield of energy dissipation; $\varphi \mathrm{E}_{0}$ - quantum yield of electron transport; $\varphi \mathrm{P}_{0}$ - maximum quantum yield of primary photochemistry; $\psi \mathrm{E}_{0}-$ probability that a trapped exciton moves an electron into the electron transport chain beyond $\mathrm{Q}_{\mathrm{A}}{ }^{-}$.

Acknowledgments: We are grateful to the Espírito Santo Research and Innovation Foundation (FAPES) for the financial support and scholarship. We are also thankful to the MS Foundation for providing the plant material and technical support during the study. The authors would also like to thank Luiz Carlos de Almeida Rodrigues, Thayna dos Santos Silva, Railda Martins Borges, João Vitor G. Silva, Myllena Lorenn Ferreira de Souza, Patrícia dos Santos Oliveira, Lucas de Almeida Leite, and Marcel Merlo Mendes for their technical assistance.

Conflict of interest: The authors declare that they have no conflict of interest. 
2015). At present, biofuels are considered a viable alternative to diversify the energy mix of countries (Costa et al. 2019a). Many studies have been conducted to increase the production of crambe in the world (Costa et al. 2019b, Li et al. 2019, Kwiatkowski et al. 2020). In Brazil, the Midwest is the main region where crambe is grown; productivity varies from 1,000 to $1,500 \mathrm{~kg} \mathrm{ha}^{-1}$ (Batista et al. 2018). New lineages have already been tested to expand the growing areas to improve productivity in Brazil, such as FMS CR 1307. This lineage is considered to be a pilot candidate and the FMS CR 1326 is also being tested by Fundação Mato Grosso do Sul (Fundação MS) (Oliveira et al. 2015).

Water deficit (WD) is the main environmental factor that limits the growth of plants throughout the world (Zhang et al. 2018a). Under WD, plants present reduced cell turgescence and stomatal conductance, diminishing the transpiration rates, which in turn impairs the assimilation of $\mathrm{CO}_{2}$ and causes damage to the reaction centers of PSII, reducing its efficiency (Mehta et al. 2010). The consequent reduction of photosynthesis lowers plant productivity (Velázquez-Márquez et al. 2015). Furthermore, when this water deficiency occurs during the flowering phenological stage, senescence of the flowers occurs (abortion), reducing the number and/or size of grains (Mathobo et al. 2017). The lower yield means a lower value and stunted or deformed grain can even prevent the sale of certain crops. Therefore, identification and selection of genotypes with morphophysiological attributes that show drought-tolerance responses during certain plant development stages, such as the flowering stage, can be promising in the maintenance of crops' production (Santos et al. 2012, Anjum et al. 2017). Boiago et al. (2018) observed a decrease in the uptake of potassium $(\mathrm{K})$ and sodium $(\mathrm{Na})$ of crambe plants (cultivar Brilhante) under WD at the flowering stage, resulting in lesser growth of the plants.

Many regions in Brazil and the rest of the world are subject to low or no rainfall during certain periods of the year. This shortage of water resources requires irrigation techniques to maintain the potential productivity of crambe. However, no studies are investigating the responses of the two mentioned crambe lineages (FMS CR 1326 and 1307) to WD. According to Vasconcelos et al. (2018) and Araújo et al. (2013), identifying species/ genotypes with the ability to adapt to water restriction is a valuable strategy to increase productivity. Thus, this work aimed to investigate the morphophysiological strategies of these two crambe lineages under WD in the flowering stage and the association with the production and germination of progeny.

\section{Materials and methods}

Plant material and experimental design: The experiment was conducted in greenhouseconditions. Seeds of Crambe abyssinica (lineages FMS CR 1326 and 1307) were obtained from Fundação Mato Grosso do Sul (Fundação MS), located in the municipality of Maracaju, Mato Grosso do Sul. The seeds were previously disinfected with $70 \%$ ethanol for $2 \mathrm{~min}, 1 \%(\mathrm{v} / \mathrm{v})$ sodium hypochlorite for $20 \mathrm{~min}$, and the fungicide Ridomil $\AA$ for $10 \mathrm{~min}$, followed by triple washing in distilled autoclaved water. The seeds were then sown to germinate in pots with a capacity of $14.3 \mathrm{~L}$ (15 seeds per pot) filled with soil (75.5\% sand, $17.2 \%$ clay, and 5.2\% silt). The soil had previously been analyzed chemically for correction of nutrients and $\mathrm{pH}$, according to the recommendations of Oliveira et al. (1991). Thirty grams of simple superphosphate were added every $30 \mathrm{~d}$ during the experiment. Besides this, insecticide (Evidence ${ }^{\circledR}$ ) and fungicide (Ridomil $囚$ ) were applied according to the manual for the crop. Twenty days after sowing, the plantlets were thinned, leaving only one plant per pot.

The pots were watered daily to keep the soil at about $80 \%$ of field capacity $\left(\approx 0.20 \mathrm{~m}^{3} \mathrm{~m}^{-3}\right)$ until the start of the flowering period when they were divided into two groups: (1) continually irrigated plants (CI) and (2) plants submitted to water deficit (WD). The WD treatment began when more than one-half $(50 \%+1)$ of the plants were undergoing inflorescence. For the FMS CR 1326 and FMS CR 1307 lineages, this period started 53 and $42 \mathrm{~d}$ after sowing, respectively. The WD was imposed by suspending the irrigation for $12 \mathrm{~d}$ (determined in preliminary studies) after the start of flowering. After this period, the irrigation was resumed daily (water resumption, WR) to maintain the soil moisture at about $80 \%$ of field capacity until the end of the experiment (end of the crop cycle, or $110 \mathrm{~d}$ after sowing).

The water levels in the soil $\left[\mathrm{m}^{3} \mathrm{~m}^{-3}\right]$ were monitored with a soil water sensor (ProCheckversion 4, Dispositivos Decagon). All the physiological measurements were carried out between 05:00 and 10:00 h with completely expanded leaves (third or fourth leaf from the apex).

Stomatal conductance and chlorophyll $\boldsymbol{a}$ fluorescence: The stomatal conductance $\left(g_{\mathrm{s}}\right)$ and chlorophyll (Chl) $a$ fluorescence transient were measured in nine plants $(n=9)$ from each treatment during the periods of $\operatorname{WD}(0,3,6$, 9 , and $12 \mathrm{~d}$ of WD) and successive WR (3 and $12 \mathrm{~d}$ of WR). The $g_{\mathrm{s}}$ was measured on the abaxial leaf surface using a leaf porometer (SC-1, Dispositivos Decagon). The $g_{\mathrm{s}}$ was expressed in $\left[\mathrm{mmol}\left(\mathrm{H}_{2} \mathrm{O}\right) \mathrm{m}^{-2} \mathrm{~s}^{-1}\right]$. The Chl $a$ fluorescence transient was measured with a portable fluorometer (Handy-PEA, Hansatech, UK). The leaves were previously adapted to the dark for $20 \mathrm{~min}$ using leaf clips (Hanstech) to assure complete oxidation of the photosynthetic system. The light intensity on the leaves, $3,000 \mu \mathrm{mol}$ (photon) $\mathrm{m}^{-2} \mathrm{~s}^{-1}$, was sufficient to generate the maximum fluorescence for all the samples. The transient fluorescence was recorded from $10 \mu \mathrm{s}$ to $1 \mathrm{~s}$. The intensity of fluorescence at $20 \mu \mathrm{s}\left(\mathrm{F}_{0}\right), 100 \mu \mathrm{s}, 300 \mu \mathrm{s}, 2 \mathrm{~ms}\left(\mathrm{~F}_{\mathrm{J}}\right)$, and $30 \mathrm{~ms}\left(\mathrm{~F}_{\mathrm{I}}\right)$, and maximum fluorescence $\left(\mathrm{F}_{\mathrm{m}}\right)$ were recorded and analyzed by the JIP-test (Strasser et al. 2004, Stirbet and Govindjee 2011, Wang et al. 2016).

Leaf and petiole anatomy: After the periods of WD (12 d) and subsequent WR (12 d), the number of xylem vessels of leaves and petioles for each treatment was determined in seven plants $(n=7)$. The samples were collected 
randomly, fixed in FAA (formaldehyde, acetic acid, and ethanol at 50\%, 0.5:0.5:9, v/v) for $72 \mathrm{~h}$, followed by storage in 50\% ethanol (Johansen 1940). Cross-sections were obtained with a double edge razor blade in the middle region of the third fully expanded leaf from the apex. The sections were observed and the images were captured with a Leica DM 1000 light microscope coupled to a Leica ICC50 HD digital camera (Wetzlar, Germany). The UTHSCSA-Imagetool ${ }^{\circledR}$ software was used to calculate the anatomical measurements revealed by the photomicrographs.

Plant growth and grain yield: On the last day of the experimental period (110 d after sowing), the root dry mass and shoot dry mass were analyzed with 16 plants from each treatment $(n=16)$. These two masses were determined in grams after the plants had been stored in paper bags for drying in a forced-air oven for $72 \mathrm{~h}$ at $60^{\circ} \mathrm{C}$.

The hundred-grain mass and grain yield per plant were evaluated after the harvest and drying of the grains. The hundred-grain mass was determined by counting and weighing eight samples $(n=8)$ of 100 grains from each treatment. The production of grains per plant was ascertained by weighing the grains produced by each plant of each treatment on a precision scale. The hundred-grain mass and grain yield were calculated with correction for $13 \%$ moisture.

Germination of progeny: At the end of the experimental period (110 d after sowing), dried seeds were sown for germination and were described as S1CI seeds [control plants - progeny of continuously irrigated plants (CI)], and S1WD (progeny of plants submitted to WD for $12 \mathrm{~d}$ ). To determine the germination percentage $(\% \mathrm{G})$ and germination speed index (GSI), the crambe seeds were previously sterilized with a $70 \%$ ethanol solution for $2 \mathrm{~min}, 1 \%(\mathrm{v} / \mathrm{v})$ sodium hypochlorite for $20 \mathrm{~min}$, and the fungicide Ridomil $\AA$ for $10 \mathrm{~min}$, followed by triple washing with autoclaved distilled water. The seeds were then placed in Gerbox ${ }^{\circledR}$ plastic boxes $(11 \times 11 \times 3 \mathrm{~cm})$ on filter paper moistened with $10 \mathrm{ml}$ of autoclaved distilled water and placed to germinate in a growth room at $25^{\circ} \mathrm{C}$ and photoperiod of $16-\mathrm{h}$ light and 8 -h dark. The germination test was carried out with 40 seeds per sample and 5 Gerbox $®$ plastic boxes $(n=5)$. The germination percentage $(\% \mathrm{G})$ was determined according to the criterion of radicle emission, and the germination speed index (GSI) was measured during $7 \mathrm{~d}$ according to Braga et al. (2019), calculated as described by Maguire (1962) using the formulas: $\% \mathrm{G}=(\Sigma \mathrm{ni} / \mathrm{N}) \times 100$ and $\mathrm{GSI}=(\mathrm{G} 1 / \mathrm{N} 1)+(\mathrm{G} 2 / \mathrm{N} 2)+\ldots(\mathrm{Gn} / \mathrm{n})$, where: $\% \mathrm{G}-$ germination percentage (with radicle emission considered to be germination); $\Sigma$ ni - total number of seeds germinated; $\mathrm{N}$ - number of seeds placed to germinate; GSI - germination speed index; G1, G2, Gn - number of seeds germinated on the first, second, and last day; N1, N2, and $\mathrm{Nn}$ - number of days since the first, second and last day of sowing.

Statistical analysis: The experimental design was completely randomized in a $2 \times 2$ factorial scheme, with two irrigation regimes [continuously irrigated plants (CI) $80 \%$ of field capacity - approximately $0.20 \mathrm{~m}^{3} \mathrm{~m}^{-3}$ of soil moisture, and plants submitted to water deficit (WD $12 \mathrm{~d}$ irrigation suspension)] and two lineages of crambe (FMS CR 1326 and 1307). The data were submitted to analysis of variance (ANOVA) and the means were compared by the Tukey's test $(p<0.05)$. The statistical analysis was applied to monitoring time and water regime, as well as genotypes and water regime. All the analyses were carried out with the Sisvar ${ }^{\circledR}$ program (Ferreira 2011).

\section{Results}

Stomatal conductance $\left(g_{\mathrm{s}}\right)$ and soil moisture: After $12 \mathrm{~d}$ of WD, symptoms (wilted leaves) were observed in all the plants. The WD at the start of the flowering period influenced the soil moisture and $g_{\mathrm{s}}$ of crambe plants (Fig. 1). The soil moisture and $g_{\mathrm{s}}$ diminished during the $12 \mathrm{~d}$ of WD. The plants of both lineages showed partial recuperation of $g_{\mathrm{s}}$ after the resumption of irrigation.

Leaf anatomy: At $12 \mathrm{~d}$ of WR, the number of leaf xylem vessels was significantly greater in the plants of the FMS CR 1326 lineage compared to the FMS CR 1307

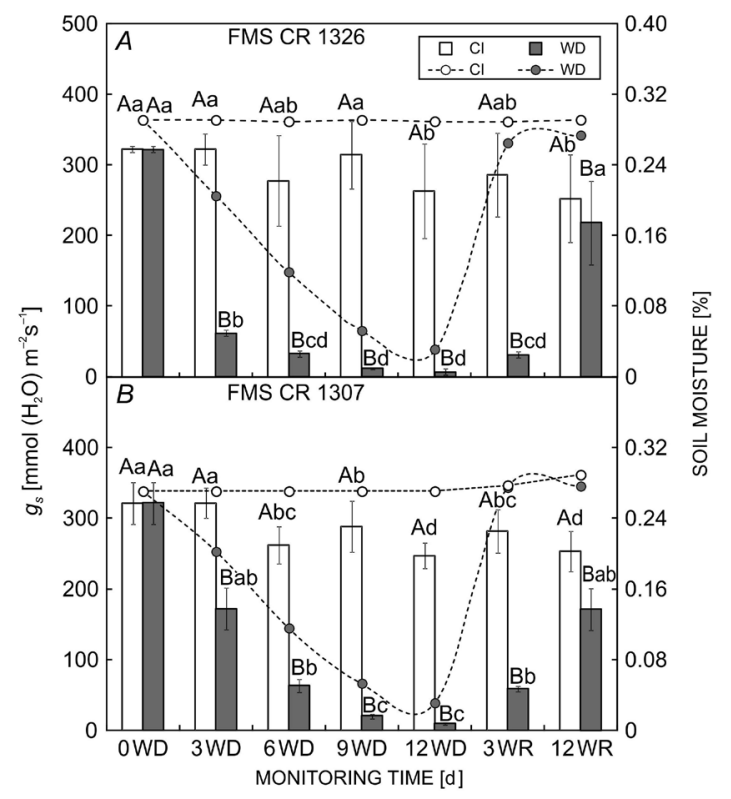

Fig. 1. Stomatal conductance, $g_{s}$ (columns - primary ordinate scale on the left) in relation to soil moisture (rows - secondary ordinate scale on the left) of two lineages of crambe, FMS CR $1326(A)$ and FMS CR $1307(B)$ submitted to water deficit $\left(0,3^{\text {rd }}, 6^{\text {th }}, 9^{\text {th }}\right.$, and $12^{\text {th }} \mathrm{d}$ of WD) followed by resumed irrigation ( $3^{\text {rd }}$ and $12^{\text {th }} \mathrm{d}$ of WR) for recuperation. For the $g_{s}$, means \pm $\mathrm{SD}(n=9)$ followed by the same letter, uppercase for water regimes (comparing the $\mathrm{CI}$ and $\mathrm{WD}$ in each monitoring day) and lowercase for monitoring days (comparing the monitoring days in each water regime), do not differ significantly by the Tukey's test $(p<0.05)$. CI - continuously irrigated plants; WD - water deficit; WR - water resumption. 
lineage after the WD and resumption of irrigation (Figs. 2, 3A). Furthermore, the lineages also responded differently regarding the number of xylem vessels per vascular bundle in the petiole (Fig. $3 B$ ). After WD and WR, the reduction was observed in the number of xylem vessels per vascular bundle in the petiole in the FMS CR 1326 lineage and an increase in the FMS CR 1307 lineage.

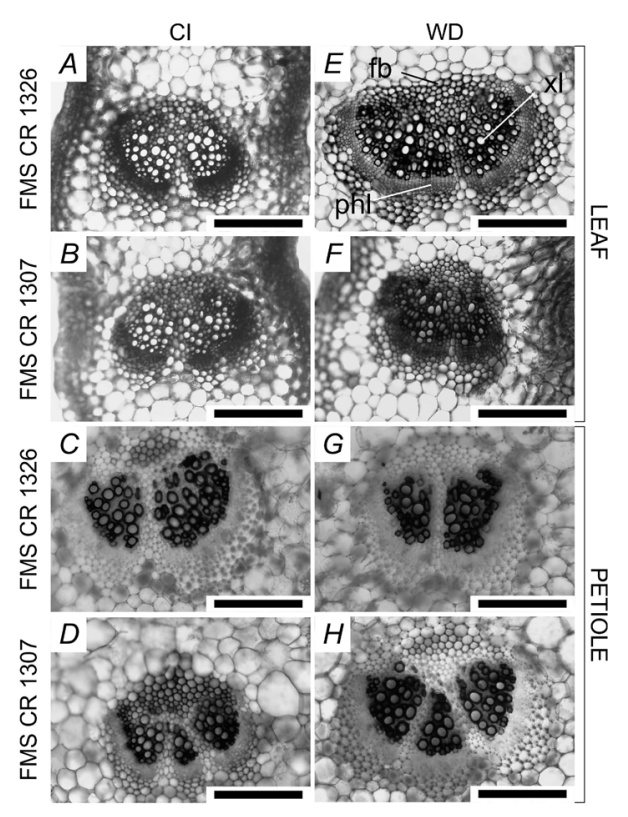

Fig. 2. Cross-sections of crambe plants (leaves and petioles) of two lineages previously submitted to $12 \mathrm{~d}$ of WD, followed by $12 \mathrm{~d}$ of WR. Bar $=50 \mu \mathrm{m}$. xl - xylem; phl - phloem; fb - fibers. CI - continuously irrigated plants; WD - water deficit; WR water resumption.

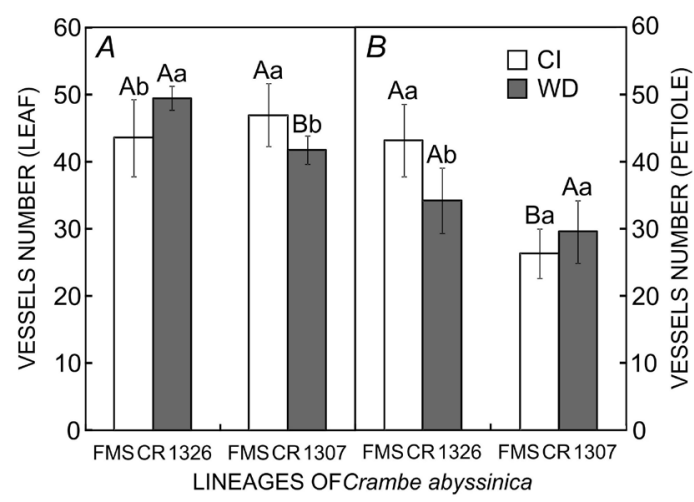

Fig. 3. Number of xylem vessels per vascular bundle in leaves $(A)$ and petioles $(B)$ of two lineages of crambe (FMS CR 1326 and FMS CR 1307) submitted to water deficit followed by water resumption. Means $\pm \mathrm{SD}(n=7)$ followed by the same letter, uppercase for lineages (comparing FMS CR 1326 and FMS CR 1307 in each water regime) and lowercase for water regimes (comparing CI and WD in each lineage), do not differ significantly by the Tukey's test, $(p<0.05)$. CI - continuously irrigated plants; WD - water deficit.
Chl $\boldsymbol{a}$ fluorescence transient - OJIP and JIP-test: The WD also affected the photosynthetic apparatus (Figs. 4, 5). The variable fluorescence related to the $\mathrm{O}(20 \mu \mathrm{s})$ and $\mathrm{J}(2 \mathrm{~ms})$ steps and between the $\mathrm{O}(20 \mu \mathrm{s})$ and $\mathrm{K}$ $(300 \mu \mathrm{s})$ steps were normalized and are reported as kinetic differences, making the $\mathrm{K}$ - and L-bands visible, respectively. The bands peaked at around 0.27 and $0.15 \mathrm{~ms}$, respectively. The two crambe lineages presented positive K- and L-bands. In the FMS CR 1326 lineage, we observed increases in $\mathrm{K}$ - and L-bands as the WD became more intense (Fig. 4A,D). For the FMS CR 1307 lineage, positive $\mathrm{K}$ - and L-bands were only observed on 9 and $12 \mathrm{~d}$ of $\mathrm{WD}$, respectively, and negative bands were observed on 3 and $6 \mathrm{~d}$ of WD, respectively, and also during 3 and $12 \mathrm{~d}$ of $\mathrm{WR}$, respectively (Fig. 4B,E). The FMS CR 1307 lineage presented lower values in the K- and L-bands in comparison to the FMS CR 1326 lineage during the periods of WD and successive WR (Fig. $4 C, F$ ). The water restriction and resumption influenced the parameters of the JIP-test. All the data were normalized to day zero of WD $(0 \mathrm{WD})$ and varied in function of the water regimes and days under water deficit/recuperation, as depicted in Fig. 5. Significant increases of $\mathrm{M}_{0}$ and reductions of $\mathrm{F}_{\mathrm{v}} / \mathrm{F}_{0}$ and $\mathrm{Sm}$ were observed for both lineages during WD and WR. Nevertheless, the FMS CR 1307 lineage presented lower values than that of the FMS CR 1326.

Concerning the parameters of the specific energy fluxes (per active RC of PSII), increases in the values of absorption (ABS/RC), trapping $\left(\mathrm{TR}_{0} / \mathrm{RC}\right)$, transport $\left(\mathrm{ET}_{0} / \mathrm{RC}\right)$, and dissipation $\left(\mathrm{DI}_{0} / \mathrm{RC}\right)$ per $\mathrm{RC}$ and decreases of RC/ABS were observed for the FMS CR 1326 lineage during the entire experimental period (Fig. $5 A$ ). However, for FMS CR 1307, these increases were observed only on the $12 \mathrm{~d}$ of WD (Fig. 5B). The FMS CR 1307 lineage presented reductions of $19.6,16.5,14.1$, and $66.2 \%$, respectively, for specific energy fluxes parameters on the 12 WD in comparison with FMS CR 1326. Reductions of the values of $\varphi \mathrm{E}_{0}$ and $\psi \mathrm{E}_{0}$ and increases of $\varphi \mathrm{D}_{0}$ were observed for the FMS CR 1326 plants exposed to WD (Fig. 5A). In contrast, for the FMS CR 1307 lineage, these increases were only observed on the $12 \mathrm{WD}$ (Fig. 5B).

The performance indexes $\left[\mathrm{PI}_{(\mathrm{ABS})}\right.$ and $\left.\mathrm{PI}_{(\mathrm{TOTAL})}\right]$ declined for the two lineages under WD (Fig. 5). However, the plants showed progressive recuperation of $\mathrm{PI}_{(\mathrm{ABS})}$ and $\mathrm{PI}_{(\mathrm{TOTAL})}$ after WR. The FMS CR 1307 plants presented the largest increases in the values of $\mathrm{PI}_{(\mathrm{ABS})}$ and $\mathrm{PI}_{\text {(TOTAL) }}$ in the period of recovery after WD (Fig. $5 B$ ).

Plant growth and grain yield: The water regimes and lineages influenced the growth traits and grain yield of the crambe plants, but this influence was independent [the factors (lineages and water regimes) did not have significant interaction]. Reductions of root and shoot dry mass were observed in the plants exposed to WD, irrespective of lineage (45.4 and $30.5 \%$, respectively, compared to the CI plants). The hundred-grain matter and production of grains per plant exposed to WD also declined, independently of crambe lineages. When the 


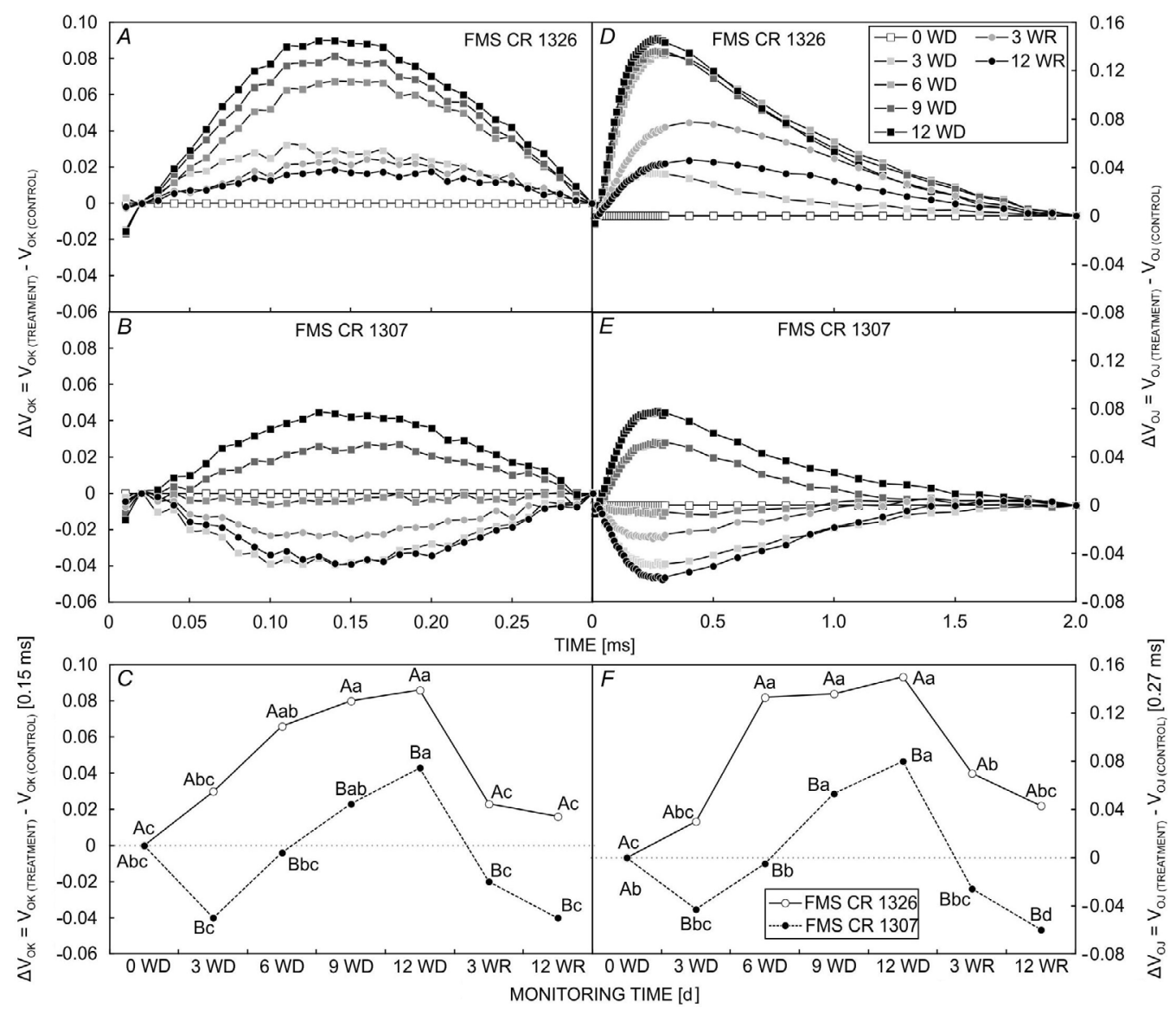

Fig. 4. Kinetic difference of $\mathrm{V}_{\mathrm{OJ}}(A, B, E)$ and $\mathrm{V}_{\mathrm{OK}}(C, D, F)$ obtained by double normalization of the $\mathrm{O}-\mathrm{J}$ steps $\left[\Delta \mathrm{V}_{\mathrm{OJ}}=\mathrm{V}_{\mathrm{OJ}(\text { treatment })}-\right.$ $\left.\mathrm{V}_{\mathrm{OJ}(\text { (control) })}\right]$ and $\mathrm{O}-\mathrm{K}$ steps $\left[\Delta \mathrm{V}_{\mathrm{OK}}=\mathrm{V}_{\mathrm{OK}(\text { treatment) }}-\mathrm{V}_{\mathrm{OK}(\text { control) }}\right]$, respectively, in two lineages of crambe (FMS CR 1326 and FMS CR 1307) submitted to water deficit $\left(0,3^{\text {rd }}, 6^{\text {th }}, 9^{\text {th }}\right.$, and $12^{\text {th }} \mathrm{d}$ of WD) followed by water resumption $\left(3^{\text {rd }}\right.$ and $12^{\text {th }} \mathrm{d}$ of WR). Means $(n=9)$ with the same letters in the row, uppercase for lineages (comparing the FMS CR 1326 and FMS CR 1307 in each monitoring day) and lowercase for monitoring days (comparing the monitoring days in each lineage), do not differ significantly by the Tukey's test $(p<0.05$ ). WD - water deficit; WR - water resumption.

hundred-grain matter was compared between the two lineages, FMS CR 1307 presented higher grain yield values than that of the FMS CR 1306 lineage (Table 1).

Germination of the progeny seeds: The WD in the flowering stage, as well as the lineages, influenced the GSI of the S1CI and S1WD of seeds (Fig. 6A). The germination percentage of the S1CI and S1WD seeds was only influenced by the water regime (Fig. 6B). Reductions in the GSI of the S1WD seeds of the FMS CR 1326 lineage were observed, as well as reductions of the germination percentage of the S1WD seeds (about 17.2\%; Fig. 6).

\section{Discussion}

In this study, we investigated how WD influences the morphophysiology of two lineages of C. abysinica at the start of the flowering stage. The plants of lineages FMS CR 1307 and FMS CR 1326 presented distinct responses during the WD and after WR. These differences were related to alterations of the anatomy and physiology, which were fundamental to maintain survival and also influenced effective grain production.

The monitoring of the control plants' transpiration of both lineages allowed noting a trend for the decrease of $g_{\mathrm{s}}$ in the leaves during the reproductive stages (flowering and grain development). This was probably related to the greater allocation of water to the flowers than would normally be required. Indeed, water is an essential resource and its scarcity limits the development of shoots, maintenance of physiology and longevity of flowers, which in turn directly influences the attraction of pollinators (Zhang et al. 2017a, Roddy et al. 2019). WD at the start of the flowering stage hampers many physiological and metabolic processes, affecting the development and grain yield of plants (Zhang et al. 2017b). Since crambe plants are pollinated by insects (Simioni et al. 2015), maintenance of good hydration of the reproductive organs is a critical aspect for attraction of pollinators, besides influencing the floral longevity and effective formation of grains (zygotic embryos). 


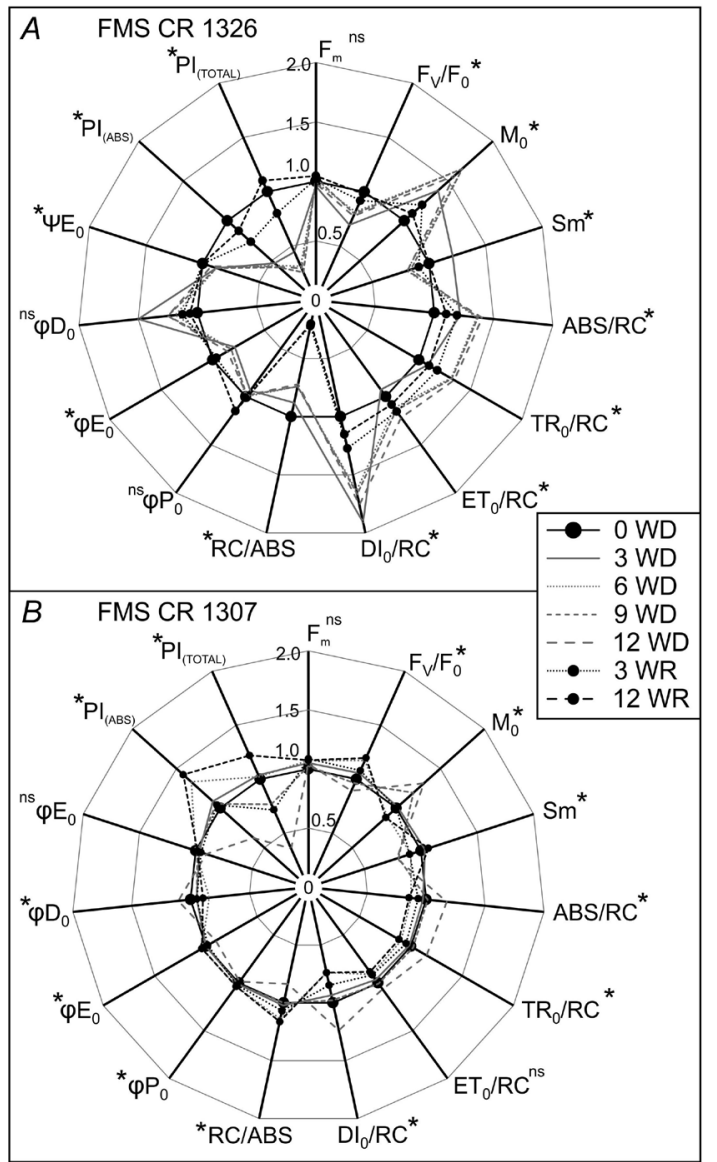

Fig. 5. JIP-test parameters of two lineages of crambe, FMS CR $1326(A)$ and FMS CR $1307(B)$, submitted to water deficit $\left(0,3^{\text {rd }}, 6^{\text {th }}, 9^{\text {th }}\right.$, and $12^{\text {th }} \mathrm{d}$ of WD) followed by water resumption $\left(3^{\text {rd }}\right.$ and $12^{\text {th }} \mathrm{d}$ of WR). Means $(n=9)$ followed by asterisks $(*)$ are significantly different in relation to monitoring days under WD and WR according to the Tukey's test, $\left({ }^{*}-p<0.05\right.$; ${ }^{\text {ns }}-$ not significant). ABS/RC - absorption flux per $\mathrm{RC} ; \mathrm{DI}_{0} / \mathrm{RC}-$ dissipated energy flux per $\mathrm{RC} ; \mathrm{ET}_{0} / \mathrm{RC}$ - electron transport flux per RC; $\mathrm{F}_{\mathrm{m}}$ - maximal fluorescence yield of the dark-adapted state; $F_{V} / F_{0}$ - ratio of photochemical to nonphotochemical quantum efficiencies (PSII potential activity); $\mathrm{M}_{0}$ - number of closed and/or inactive reaction centers; $\mathrm{PI}_{(\mathrm{ABS})}$ - performance index based on absorption; $\mathrm{PI}_{\text {(TOTAL) }}$ - overall performance index, which measures the performance up until the final electron acceptors of PSI; RC/ABS - total number of active reaction center per absorption; $\mathrm{Sm}$ - assumed proportional to the number of reduction and oxidation of one $\mathrm{Q}_{\mathrm{A}}{ }^{-}$molecule during the fast OJIP transient, and therefore related to the number of electron carriers per electron transport chain; $\mathrm{TR}_{0} / \mathrm{RC}$ - trapping flux per RC; WD - water deficit; WR - water resumption; $\varphi \mathrm{D}_{0}-$ quantum yield of energy dissipation; $\varphi \mathrm{E}_{0}$ - quantum yield of electron transport; $\varphi \mathrm{P}_{0}-$ maximum quantum yield of primary photochemistry; $\psi \mathrm{E}_{0}$ - probability that a trapped exciton moves an electron into the electron transport chain beyond $\mathrm{Q}_{\mathrm{A}}{ }^{-}$.

The reductions of $g_{\mathrm{s}}$ observed as at 3 WD allow inferring that closing of the stomatal pores (ostioles) occurred. Plants close their stomata to limit water loss and reduce the negative effects of WD. This physiological response can be mediated by abscisic acid (ABA) (Saradadevi et al. 2017, Kuromori et al. 2018). The biosynthesis of this hormone is related to the regulation of the expression of genes responsive to water stress in the roots (Rasheed et al. 2016). In this study, the reduction of the soil moisture was more drastic on the $12 \mathrm{WD}$, which induced a sharper decline of the transpiration via stomatal conductance. These modulations of transpiration and water conductivity are keys for drought tolerance because they decelerate the loss of water to the atmosphere (Zhang et al. 2018a).

During WD, the water conductivity can be compromised due to the loss of functionality of the xylem vessels by an embolism (Tombesi et al. 2015). The vulnerability of leaves induced by embolism under stress conditions provoked by drought can lead to leaf mortality (Cardoso et al. 2020). Therefore, phenotypic plasticity of the anatomictraits involved in water conductivity is fundamental for plants to adjust to water stress. In this study, the two crambe lineages presented different responses to the water stress conditions imposed. The plants of the FMS CR 1326 lineage had a higher number of xylem vessels per vascular bundle in the new leaves formed after the WD period and subsequent WR. This can be interpreted as a compensatory response to losses of water conductivity by embolism. In contrast, the FMS CR 1307 plants had reduced water conductivity due to a smaller number of vessel elements. This makes sense because water conductivity is modulated by the diameter and/or the number of vessels in the xylem (Tulik et al. 2010, Zhang et al. 2018b). A decrease in water conductivity due to alterations in the number or diameter of xylem vessels can contribute to reduce the transpiration through the stomata and increase the drought tolerance, as reported by Zhang et al. (2018b) and El-Sayed et al. (2019). Indeed, the adjustments of water conductivity (confirmed by the values of $g_{s}$ ) observed in the FMS CR 1307 plants were efficient and permitted a faster recovery of these plants after 3 WR (demonstrated by the analyses of Chl $a$ fluorescence).

Water deficit regimes also influence the performance of the photosynthetic apparatus. In conditions of water restriction, the analysis of $\mathrm{Chl} a$ fluorescence consistently shows positive values for K- and L-bands (Falqueto et al. 2017, Martins et al. 2017, ). Positive values of K-and L-bands indicate physiological disturbances in response to stress (Meng et al. 2016). The positive amplitudes of the K-band of both lineages under WD indicated partial inactivation of the oxygen-evolving complex (OEC) (Rosa et al. 2018). This behavior was confirmed in the present study, by the reduction of $F_{v} / F_{0}$ in the FMS CR 1326 plants on all WD and WR periods. This result suggests reduced efficiency on the donor side of PSII, i.e., inactivation of the OEC (Kalaji et al. 2016). The FMS CR 1307 plants were more tolerant and only showed reductions in the $\mathrm{F}_{\mathrm{v}} / \mathrm{F}_{0}$ values at $9 \mathrm{WD}$ and $12 \mathrm{WD}$.

The positive amplitudes of the L-band of both lineages can be interpreted as inhibition of the donation of electrons to YZ (Tyr161 of the protein D1) and disorganization of PSII (Huang et al. 2017). The rising 
Table 1. Plant growth and grain yield of crambe as a function of lineages (FMS CR 1326 and FMS CR 1307) or water regimes $(\mathrm{CI}$ and WD). For water regime or lineages of crambe, means $\pm \mathrm{SD}$ (growth traits: $n=16$; grain yield: $n=8$ ) followed by the same letter in the column do not differ significantly according to the Tukey's test $(p<0.05)$. CI - continuously irrigated plants; WD - water deficit.

\begin{tabular}{lllll}
\hline Water regime & $\begin{array}{l}\text { Root dry mass } \\
\text { [g per plant] }\end{array}$ & $\begin{array}{l}\text { Shoot dry mass } \\
\text { [g per plant] }\end{array}$ & $\begin{array}{l}\text { 100-grain mass } \\
{[\mathrm{g}]}\end{array}$ & $\begin{array}{l}\text { Production of grains per plant } \\
\text { [g per plant] }\end{array}$ \\
\hline CI & $0.011 \pm 0.005^{\mathrm{a}}$ & $0.085 \pm 0.018^{\mathrm{a}}$ & $2.43 \pm 0.50^{\mathrm{a}}$ & $61.40 \pm 5.94^{\mathrm{a}}$ \\
WD & $0.006 \pm 0.003^{\mathrm{b}}$ & $0.059 \pm 0.014^{\mathrm{b}}$ & $1.76 \pm 0.41^{\mathrm{b}}$ & $35.70 \pm 8.01^{\mathrm{b}}$ \\
Lineages of crambe & $\begin{array}{l}\text { Root dry mass } \\
\text { [g per plant] }\end{array}$ & $\begin{array}{l}\text { Shoot dry mass } \\
\text { [g per plant] }\end{array}$ & $\begin{array}{l}100 \text {-grain mass } \\
{[\mathrm{g} \text { ] }}\end{array}$ & $\begin{array}{l}\text { Production of grains per plant } \\
\text { [g per plant] }\end{array}$ \\
\hline FMS CR 1326 & $0.011 \pm 0.005^{\mathrm{a}}$ & $0.081 \pm 0.014^{\mathrm{a}}$ & $1.72 \pm 0.36^{\mathrm{b}}$ & $47.75 \pm 16.91^{\mathrm{a}}$ \\
FMS CR 1307 & $0.006 \pm 0.003^{\mathrm{b}}$ & $0.063 \pm 0.022^{\mathrm{b}}$ & $2.47 \pm 0.48^{\mathrm{a}}$ & $49.46 \pm 20.40^{\mathrm{a}}$ \\
\hline
\end{tabular}

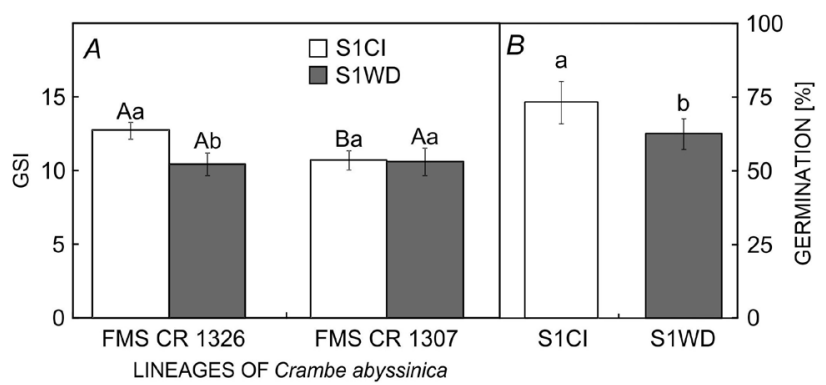

Fig. 6. Germination speed index (GSI) and germination rate [\%] of the progeny of crambe plants previously submitted to water deficit followed by water resumption. $(A)$ GSI of the progeny of two lineages of crambe (FMS CR 1326 and FMS CR 1307) submitted to water deficit followed by water resumption and $(B)$ germination rate of the progeny of crambe plants, irrespective of the lineage (only influenced by the previous water regime treatments). Means $\pm \mathrm{SD}(n=8)$ followed by the same letter, uppercase for lineages (comparing the FMS CR 1326 and FMS CR 1307 in each water regime) and lowercase for water regime (comparing the S1CI and S1WD), do not differ significantly according to the Tukey's test $(p<0.05)$. S1CI - seeds of progeny of continuously irrigated plants; S1WD - seeds of progeny of plants submitted to water deficit.

increase of the positive amplitudes in the L-band of the FMS CR 1326 plants suggests that each day of WD aggravates the damages to energy connectivity or grouping among the PSII units. For the FMS CR 1307 plants, the photochemical damages began on the 9 WD. Between the two lineages, FMS CR 1307 was better able to maintain the balance between the electrons at the donor and acceptor sites of PSII when submitted to moderate WD (6 WD), but not intense WD (9 WD and 12 WD). In turn, the FMS CR 1326 plants were unable to maintain the equilibrium between electrons even at the start of the water deficit (3 WD).

$\mathrm{M}_{0}$ is associated with the number of closed and/or inactive reaction centers (Einali and Shariati 2015) and the electron transport between quinone $A\left(Q_{A}\right)$ and quinone $B\left(Q_{B}\right)$. An increase of this parameter's values can indicate inhibition on the acceptor side of PSII (Wang et al. 2016). Therefore, the reduction of the values of $\mathrm{M}_{0}$ of the FMS CR 1307 plants indicates total recovery in the rehydration period, besides an increase of primary photochemical activity. The $F_{v} / F_{0}$ ratio is considered the most sensitive parameter of the electron transport chain, since it is proportional to the activity of the OEC, i.e., of the donor side of PSII. An increase of this parameter indicates an improved electron transport (GhassemiGolezani and Lotfi 2015). The reductions of $F_{v} / F_{0}$ and Sm observed for the FMS CR 1326 plants indicate greater impairment of the electron transfer system caused by WD.

The increases of $\mathrm{ABS} / \mathrm{RC}$ values and reductions of $\mathrm{RC} / \mathrm{ABS}$ in the FMS CR 1326 lineage also indicate reduced stability of the $\mathrm{RC}$, i.e., a reduction in the connection with the light-harvesting antenna complexes (Chen et al. 2014, Li et al. 2020). For both lineages, an increase of $\mathrm{ABS} / \mathrm{RC}$ resulted in increases of $\mathrm{TR}_{0} / \mathrm{RC}$ and $\mathrm{DI}_{0} / \mathrm{RC}$. According to Souza et al. (2019), increases in the values of $\mathrm{TR}_{0} / \mathrm{RC}$ proportional to increases of $\mathrm{ABS} / \mathrm{RC}$ indicate impairment of OEC due to suppressed repair of the damaged PSII (Takahashi and Murata 2008). This response was confirmed by the increase of the positive values of the $\mathrm{K}$-band and reductions of $\mathrm{F}_{\mathrm{v}} / \mathrm{F}_{0}$, which were more pronounced in the FMS CR 1326 plants. Besides this, the reductions of $\varphi \mathrm{E}_{0}$ and $\psi \mathrm{E}_{0}$ and increases of $\varphi \mathrm{D}_{0}$ observed in the FMS CR 1326 plants submitted to WD also indicate that the energy absorbed was not trapped and used to reduce the $\mathrm{Q}_{\mathrm{A}}$, which increased the loss of energy by dissipation $\left(\varphi \mathrm{D}_{0}\right)$ (Meng et al. 2016, Martins et al. 2019). In rice plants (Oryza sativa L. of the Liangyoupeijiu genotype), response to WD was also related to increases in the energy dissipation flux $\left(\mathrm{DI}_{0} / \mathrm{RC}\right)$, as well as higher quantum yield for energy dissipation $\left(\varphi \mathrm{D}_{0}\right)$ and decrease of $\mathrm{RC} / \mathrm{ABS}$, indicating lower energy use during the WD period (Wang et al. 2017).

The performance indexes $\left[\mathrm{PI}_{(\mathrm{ABS})}\right.$ and $\left.\mathrm{PI}_{(\mathrm{TOTAL})}\right]$ are considered the most sensitive parameters of the JIP-test. According to Yusuf et al. (2010), reductions of the PI values denote a decrease in the energy conservation potential of the photosynthetic apparatus. The reductions of $\mathrm{PI}_{(\mathrm{ABS})}$ and $\mathrm{PI}_{(\mathrm{TOTAL})}$ in the two crambe lineages analyzed showed reduced efficiency of the energy fluxes of the electron transport chain under WD. In general, the FMS CR 1326 lineage suffered greater impairment of the photosynthetic apparatus under WD, i.e., the worse 
performance of the photosynthetic apparatus, while the FMS CR 1307 plants presented increases in these parameters after rehydration (WR), revealing the ability to maintain efficient energy transfer and capture of photosystem PSII, indicating greater recuperation and photochemical tolerance to WD. This better performance of the photosynthetic apparatus was related to the alterations of the water conductivity and consequent more efficient use of water in adverse conditions.

Water shortage often stunts the vegetative growth of plants (Covre et al. 2016), as observed in this study. The reduction of the accumulation of dry matter of the crambe plants under stress was associated with the worse performance of the photosystems. This response may be associated with hormonal balance. According to Masondo et al. (2019), the increased concentration of endogenous ABA activates various response mechanisms to drought stress, impairing the performance of the photosynthetic apparatus. Differences in the accumulation of dry biomass and embryonic grain development in the plants submitted to temporary water deprivation were observed. The FMS CR 1326 plants presented greater accumulation of dry mass (vegetative growth), but the effective grain production was partially impaired since many grains were unfilled due to the inability to form zygotic embryos. Hence, there was a preponderance of energy drain (embryos) over energy source (mother plant). On the other hand, the FMS CR 1307 plants accumulated less dry biomass but had greater hundredgrain mass. This means that most of the grains were filled with zygotic embryos. The development of viable seeds (with all components such as cotyledons, embryo, seed coat, and endosperm) demands considerable energy; hence the preponderance of energy drains to source. The energy synthesized from sucrose in green (photosynthetically active) tissues is carried through the phloem to support the growth and maturation of the grains (seeds) (Aguirre et al. 2018). We suggest that the lower accumulation of dry biomass by the FMS CR 1307 plants occurred due to the energy demand for the development of embryos. This greater energy demand did not occur in the FMS CR 1326 plants in the final reproduction stages because of the lower number of zygotic embryos per plant (hundredgrain mass).

WD can also cause consistent impacts on the successive processes of plants (Shi et al. 2018), such as seed development of progeny. Exposure to environmental factors of the mother plant can have subsequent effects on the seeds of the progeny (Postma and Agren 2015, Chen et al. 2020). The alterations in the GSI of the seeds generated by the FMS CR 1326 plants might be associated with the endogenous content of $\mathrm{ABA}$ in the seeds. Likewise, the lower germination rate of the seeds (less vigor) produced by the mother plants previously exposed to WD might be involved with the accumulation of $\mathrm{ABA}$ in the seed endosperm. This hormone plays a central role in seed dormancy and germination (Wasilewska et al. 2008).

Conclusions: The two crambe lineages evaluated showed distinct responses to $\mathrm{WD}$ at the start of the flowering stage. The FMS CR 1326 plants had less ability for photochemical adjustment and lower effective grain yield when submitted to water restriction. The water stress produced a residual effect on the progeny, resulting in less vigorous seeds. The FMS CR 1307 plants had a greater ability to maintain the performance of the photosynthetic apparatus under WD due to alterations in the water conductivity and thus more efficient use of water. The FMS CR 1307 lineage is thus more tolerant to water stress during the flowering stage and has a greater effective grain yield.

\section{References}

Aguirre M., Kiegle E., Leo G., Ezquer I.: Carbohydrate reserves and seed development: an overview. - Plant Reprod. 31: 263290, 2018.

Anjum S.A., Ashraf U., Zohaib A. et al.: Growth and development responses of crop plants under drought stress: a review. Zemdirbyste 104: 267-276, 2017.

Araújo L.F., Bertini C.H.C.M., Bleicher E. et al.: [Phenologic, agronomic and technological characteristics of the fiber of different cultivars of upland cotton.] - Rev. Bras. Ciên. Agr. 8: 8448-453, 2013. [In Portuguese]

Batista P.F, Costa A.C., Müller C. et al.: Nitric oxide mitigates the effect of water deficit in Crambe abyssinica. - Plant Physiol. Bioch. 129: 310-322, 2018.

Boiago N.P., Fortes A.M.T., Coelho S.R.M. et al:: Morphophysiological and nutritional characteristics of Crambe abyssinica Hochst under hydric restriction in different phonological stages. - Acta Physiol. Plant. 40: 99, 2018.

Braga P.C.S., Martins J.P.R., Pacheco M.V. et al.: Germination and seedling growth of genotypes Crambe abyssinica submitted to water deficit. - J. Agr. Sci. 11: 23-34, 2019.

Cardoso A.A., Batz T.A., McAdam S.A.M.: Xylem embolism resistance determines leaf mortality during drought in Persea americana. - Plant Physiol. 182: 547-554, 2020.

Chen F., Zhou W., Yin H. et al.: Shading in mother plant during seed development promotes subsequent seed germination in soybean. - J. Exp. Bot. 71: 2072-2084, 2020.

Chen S.G., Strasser R.J., Qiang S.: In vivo assessment of effect of phytotoxin tenuazonic acid on PSII reaction centers. - Plant Physiol. Bioch. 84: 10-21, 2014.

Costa E., Almeida M.F., Alvim-Ferraz C., Dias J.M.: Cultivation of Crambe abyssinica non-food crop in Portugal for bioenergy purposes: agronomic and environmental assessment. - Ind. Crop. Prod. 139: 111501, 2019a.

Costa E., Almeida M.F., Alvim-Ferraz C., Dias J.M.: The cycle of biodiesel production from Crambe abyssinica in Portugal. Ind. Crop. Prod. 129: 51-58, $2019 \mathrm{~b}$.

Covre A.M., Partelli F.L., Bonomo R. et al.: Vegetative growth of Conilon coffee plants under two water conditions in the Atlantic region of Bahia State, Brazil. - Acta Sci.-Agron. 38: 535-545, 2016.

Einali A., Shariati M.: Effects of propyl gallate on photosystem II efficiency in Dunaliella bardawil under high illumination as investigated by chlorophyll fluorescence measurements. Theor. Exp. Plant Physiol. 27: 61-73, 2015.

El-Sayed I.M., Shaaban S.A., Taha L.S., Mahgoub M.H.: Anatomical structure and micropropagation ability of Populus alba L. under effect of drought stress. - Plant Arch. 19: 2655-2663, 2019.

Falqueto A.R., da Silva Júnior R.A., Gomes M.T.G. et al.: Effects of drought stress on chlorophyll $a$ fluorescence in two rubber tree clones. - Sci. Hortic.-Amsterdam 224: 
238-243, 2017

Ferreira D.F.: Sisvar: a computer statistical analysis system. Ciênc. Agrotec. 35: 1039-1042, 2011.

Ghassemi-Golezani K., Lotfi R.: The impact of salicylic acid and silicon on chlorophyll $a$ fluorescence in mung bean under salt stress. - Russ. J. Plant Physiol. 62: 611-616, 2015.

Huang M., Zhu H., Zhang J. et al.: Toxic effects of cadmium on tall fescue and different responses of the photosynthetic activities in the photosystem electron donor and acceptor sides. - Sci. Rep.-UK 7: 14387, 2017.

Johansen D.A.: Plant Microtechnique. Pp. 523. McGraw-Hill Book Co., New York-London 1940.

Kalaji H.M., Jajoo A., Oukarroum A. et al.: Chlorophyll a fluorescence as a tool to monitor physiological status of plants under abiotic stress conditions. - Acta Physiol. Plant. 38: 102, 2016.

Kuromori T., Seo M., Shinozaki K.: ABA transport and plant water stress responses. - Trends Plant Sci. 23: 513-522, 2018.

Kwiatkowski J., Krzyżaniak M., Załuski D. et al.: The physical properties of fruits and the physiological quality of seeds of selected crambe genotypes. - Ind. Crop. Prod. 145: 111977, 2020.

Lalas S., Gortzi O., Athanasiadis V. et al.: Full characterization of Crambe abyssinica Hochst. seed oil. -J. Am. Oil Chem. Soc. 89: 2253-2258, 2012.

Li L., Pan X.L., Mu G.J.: Toxic effects of potassium permanganate on photosystem II activity of cyanobacteria Microcystis aeruginosa. - Photosynthetica 58: 54-60, 2020.

Li X., Guan R., Fan J., Zhu L.-H.: Development of industrial oil crop Crambe abyssinica for wax ester production through metabolic engineering and cross breeding. - Plant Cell Physiol. 60: 1274-1283, 2019.

Maguire J.D.: Speed of germination aid in selection and evaluation for seedling emergence and vigor. - Crop Sci. 2: 176-177, 1962

Martins J.P.R., Rodrigues L.C.A., Silva T.S. et al.: Sources and concentrations of silicon modulate the physiological and anatomical responses of Aechmea blanchetiana (Bromeliaceae) during in vitro culture. - Plant Cell Tiss. Org. 137: 397-410, 2019.

Martins R.F.A., Souza A.F.C., Pitol C., Falqueto A.R.: Physiological responses to intense water deficit in two genotypes of crambe (Crambe abyssinica Hochst.). - Aust. J. Crop Sci. 11: 821-827, 2017.

Masondo N.A., Aremu A.O., Kulkarni M.G. et al: How do different watering regimes affect the growth, chlorophyll fluorescence, phytohormone, and phenolic acid content of greenhouse-grown Ceratotheca triloba? - J. Plant Growth Regul. 38: 385-399, 2019.

Mathobo R., Marais D., Steyn J.M.: The effect of drought stress on yield, leaf gaseous exchange and chlorophyll fluorescence of dry beans (Phaseolus vulgaris L.). - Agr. Water Manage. 180: 118-125, 2017.

Mehta P., Jajoo A., Mathur S., Bharti S.: Chlorophyll a fluorescence study revealing effects of high salt stress on Photosystem II in wheat leaves. - Plant Physiol. Bioch. 48: 16-20, 2010.

Meng L.L., Song J.F., Wen J. et al.: Effects of drought stress on fluorescence characteristics of photosystem II in leaves of Plectranthus scutellarioides. - Photosynthetica 54: 414421, 2016.

Oliveira A.J., Garrido W.E., Araujo J.D. et al.: [Research Methods in Soil Fertility]. Pp. 392. EMBRAPA-SEA, Brazil 1991. [In Portuguese]

Oliveira R.C., Reis A.C.C.S., Aguiar C.G. et al.: [Crambe cultivation management.] - In: Oliveira R.C., Reis A.C.C.S.,
Aguiar C.G. et al. (ed.): [Crambe Agro-industrialization]. Pp. 15-22. ASSOESTE, Cascavel 2015. [In Portuguese]

Postma F.M., Agren J.: Maternal environment affects the genetic basis of seed dormancy in Arabidopsis thaliana. Mol. Ecol. 24: 785-797, 2015.

Rasheed S., Bashir K., Matsui A. et al.: Transcriptomic analysis of soil-grown Arabidopsis thaliana roots and shoots in response to a drought stress. - Front. Plant Sci. 7: 180, 2016.

Roddy A.B., Jiang G.-F., Cao K. et al.: Hydraulic traits are more diverse in flowers than in leaves. - New Phytol. 223: 193-203, 2019.

Rosa W.S., Martins J.P.R., Rodrigues E.S. et al.: Photosynthetic apparatus performance in function of the cytokinins used during the in vitro multiplication of Aechmea blanchetiana (Bromeliaceae). - Plant Cell Tiss. Org. 133: 339-350, 2018.

Santos D., Guimarães V.F., Klein J. et al:: [Wheat cultivars submitted to water deficit at the beginning of flowering in greenhouse.] - Rev. Bras. Eng. Agr. Amb. 16: 836-842, 2012. [In Portuguese]

Saradadevi R., Palta J.A., Siddique K.H.M.: ABA-mediated stomatal response in regulating water use during the development of terminal drought in wheat. - Front. Plant Sci. 8: 1251, 2017.

Shi W., Li X., Schmidt R.C. et al.: Pollen germination and in vivo fertilization in response to high-temperature during flowering in hybrid and inbred rice. - Plant Cell Environ. 41: 1287-1297, 2018.

Simioni L.C., Mussury R.M., Mauad M. et al.: Plant-pollinator interactions in Crambe abyssinica Hochst. (Brassicaceae) associated with environmental variables. - An. Acad. Bras. Ciênc. 87: 137-145, 2015.

Souza A.F.C., Martins J.P.R., Gontijo A.B.P.L., Falqueto A.R.: Selenium improves the transport dynamics and energy conservation of the photosynthetic apparatus of in vitro grown Billbergia zebrina (Bromeliaceae). - Photosynthetica 57: 931-941, 2019.

Stirbet A., Govindjee: On the relation between the Kautsky effect (chlorophyll $a$ fluorescence induction) and photosystem II: basics and applications of the OJIP fluorescence transient. - J. Photoch. Photobio. B 104: 236-257, 2011.

Strasser R.J., Tsimilli-Michael M., Srivastava A.: Analysis of the chlorophyll $a$ fluorescence transient. - In: Papageorgiou G.C., Govindjee (ed.): Chlorophyll $a$ Fluorescence: A Signature of Photosynthesis. Advances in Photosynthesis and Respiration. Pp. 321-362. Springer, Dordrecht 2004.

Takahashi S., Murata N.: How do environmental stresses accelerate photoinhibition? - Trends Plant Sci. 13: 178-182, 2008.

Tombesi S., Nardini A., Frioni T. et al.: Stomatal closure is induced by hydraulic signals and maintained by ABA in drought-stressed grapevine. - Sci. Rep.-UK 5: 12449, 2015.

Tulik M., Marciszewska K., Adamczyk J.: Diminished vessel diameter as a possible factor in the decline of European ash (Fraxinus excelsior L.). - Ann. For. Sci. 67: 103, 2010.

Vasconcelos U.A.A., Cavalcanti J.J.V., Farias F.J.C. et al.: Diallel analysis in cotton (Gossypium hirsutum L.) for water stress tolerance. - Crop Breed. Appl. Biotechnol. 18: 24-30, 2018.

Velázquez-Márquez S., Conde-Martínez V., Trejo C. et al.: Effects of water deficit on radicle apex elongation and solute accumulation in Zea mays L. - Plant Physiol. Bioch. 96: 29-37, 2015.

Wang Y.P., Tang J.S., Chu C.Q., Tian J.: A preliminary study on the introduction and cultivation of Crambe abyssinica in China, an oil plant for industrial uses. - Ind. Crop. Prod. 12: 47-52, 2000. 
Wang Y.W., Xu C., Lv C.F. et al.: Chlorophyll $a$ fluorescence analysis of high-yield rice (Oryza sativa L.) LYPJ during leaf senescence. - Photosynthetica 54: 422-429, 2016.

Wang Y.W., Xu C., Wu M., Chen G.X.: Characterization of photosynthetic performance during reproductive stage in high-yield hybrid rice LYPJ exposed to drought stress probed by chlorophyll $a$ fluorescence transient. - Plant Growth Regul. 81: 489-499, 2017.

Wasilewska A., Vlad F., Sirichandra C. et al.: An update on abscisic acid signaling in plants and more... - Mol. Plant 1: 198-217, 2008.

Yusuf M.A., Kumar D., Rajwanshi R. et al:: Overexpression of $\gamma$-tocopherol methyl transferase gene in transgenic Brassica juncea plants alleviates abiotic stress: Physiological and chlorophyll $a$ fluorescence measurements. BBA-Bioenergetics 1797: 1428-1438, 2010.
Zhang F.P., Yang Y.J., Yang Q.Y. et al.: Floral mass per area and water maintenance traits are correlated with floral longevity in Paphiopedilum (Orchidaceae). - Front. Plant Sci. 8: $501,2017 \mathrm{a}$.

Zhang J., Zhang H., Srivastava A.K. et al.: Knockdown of rice microRNA166 confers drought resistance by causing leaf rolling and altering stem xylem development. - Plant Physiol. 176: 2082-2094, 2018 b.

Zhang M., Wang L.F., Zhang K. et al.: Drought-induced responses of organic osmolytes and proline metabolism during preflowering stage in leaves of peanut (Arachis hypogaea L.). J. Integr. Agr. 16: 2197-2205, 2017b.

Zhang S.H., Xu X.F., Sun Y.M. et al.: Influence of drought hardening on the resistance physiology of potato seedlings under drought stress. - J. Integr. Agr. 17: 336-347, 2018 a.

(C) The authors. This is an open access article distributed under the terms of the Creative Commons BY-NC-ND Licence. 